\title{
Rapid Application Development untuk Sistem Informasi Payroll Berbasis Web
}

\section{Rapid Application Development for Web-based Payroll Information System}

Ni Wayan Sumartini Saraswati, Ni Wayan Wardani, Ketut Laksmi Maswari, I Dewa Made Krishna Muku

STMIK STIKOM, Indonesia

\section{Article Info}

Article history:

Received, 06 November 2020

Revised, 06 Januari 2021

Accepted, 17 Maret 2021

\section{Kata Kunci:}

Payroll

Sistem Informasi

Aplikasi Website

Rapid Application Development

Pengujian blackbox

\section{Keywords:}

Payroll

Information System

Website

$R A D$

Blackbox testing

\begin{abstract}
ABSTRAK
Pertambahan jumlah karyawan Sekolah Tinggi Manajemen Informatika dan Komputer / STMIK STIKOM Indonesia disertai dengan segala perubahan data di dalamnya menyebabkan perlu usaha ekstra dalam menyusun daftar gaji tiap bulannya. Adanya sistem informasi penggajian diyakini dapat membuat penyusunan daftar gaji menjadi lebih efektif dan efisien. dalam penelitian ini dilakukan pengembangan sistem informasi payroll berbasis website yang sesuai dengan proses bisnis di STMIK STIKOM Indonesia. Metode pengembangan perangkat lunak Rapid Application Development / RAD dipilih karena metode ini cocok dengan target waktu pengembangan aplikasi yang singkat. Berdasarkan pengujian fungsionalitas sistem menggunakan metode blackbox testing diperoleh kesimpulan bahwa sistem yang dikembangkan telah mampu memenuhi kebutuhan fungsional sistem dengan baik.
\end{abstract}

\section{ABSTRACT}

The increase of employees number of STMIK STIKOM Indonesia followed by all changes in the employee data caused extra effort to compile a monthly salary list. It is believed that the existence of a payroll information system can make the preparation of salary lists more effective and efficient. In this research, the development of a website-based payroll information system is carried out in accordance with the business processes in STMIK STIKOM Indonesia. The rapid application development was chosen because this method is suitable for a short target application development time. Based on the system functionality testing using the blackbox testing method, it is concluded that the system developed has been able to meet the functional requirements of the system well.

This is an open access article under the CC BY-SAlicense.

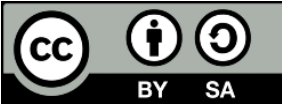

Penulis Korespondensi:

Ni Wayan Sumartini Saraswati,

Program Studi Teknik Informatika,

STMIK STIKOM, Indonesia,

Email: sumartini.saraswati@gmail.com 


\section{PENDAHULUAN}

Sistem penggajian dalam manajemen sering juga disebut sebagai payroll. Payroll dari sisi akuntansi dan ekonomi diartikan sebagai suatu metode penggajian yang dirancang khusus oleh suatu perusahaan agar proses penggajian para karyawan menjadi lebih efektif dan efisien [1]. Otomatisasi dalam penggajian tiap bulannya akan mempersingkat waktu yang dibutuhkan oleh manajemen dalam menyelesaikan salah satu proses bisnis kritis perusahaan [2]. Setiap perusahaan idealnya memiliki sistem payroll agar dapat menangani penggajian karyawan dengan baik dan tanpa adanya kesalahan [3].

Ada beberapa alasan mengapa penting bagi perusahaan untuk menerapkan sistem payroll, antara lain adalah sistem payroll akan menangani keamanan data karyawan dan penggajian dengan baik. Seperti kita ketahui masalah gaji adalah masalah yang sensitif, kerahasiaan gaji karyawan lebih banyak menjadi pilihan untuk menghindari dampak sosial dan psikologis akibat adanya kesenjangan nominal gaji yang diterima antar karyawan. Alasan kedua adalah sistem payroll yang baik memungkinkan keadilan dalam pemberian gaji dapat tercipta berdasarkan kinerja dan beban kerja karyawan. Hal ini mengingat bahwa pemberian gaji merupakan bentuk apresiasi dari perusahaan atas jasa yang diberikan oleh karyawan. Alasan ketiga adalah dengan adanya sistem payroll manajemen dapat memantau perkembangan karyawan dan mengambil keputusan yang sesuai berdasarkan kebutuhan perusahaan. Alasan terakhir sistem payroll juga memungkinkan perusahaan menangani gaji dan atribut rinciannya dengan lebih teliti. Hal ni dikarenakan rincian dalam sebuah gaji akan meningkatkan semangat karyawan dalam berkerja dikarenakan perhitungan pembayaran gaji sesuai dengan perbedaan kontribusinya pada perusahaan. Meskipun fungsinya penting dalam proses organisasi, studi tentang pemrosesan penggajian cukup terbatas, dibandingkan dengan sistem pemrosesan transaksi lain seperti penjualan dan pembelian. Hal ini dikuatkan oleh studi literatur yang dilakukan oleh Fariza dkk [4][5].

$R A D$ adalah sebuah metodologi yang digunakan untuk membangun perangkat lunak. $R A D$ merupakan model proses perangkat lunak yang menekankan pada daur pengembangan hidup yang singkat. $R A D$ merupakan versi adaptasi cepat dari model waterfall [6]. Model RAD memiliki 3 tahapan sebagai berikut ; Rencana Kebutuhan (Requirement Planning), Proses Desain Sistem (Design System), dan Implementasi (Implementation)[7]. Requirement planning melibatkan pengguna untuk merancang dan membangun sistem (kegiatan ini dilakukan secara berulang-ulang hingga mencapai kesepakatan bersama) [8]. Metode ini mampu untuk mengurangi waktu dalam pembangunan perangkat lunak. Model RAD memiliki empat tahap utama, yaitu perencanaan kebutuhan, desain pengguna, konstruksi, dan implementasi. Dalam implementasi, ada tiga cara implementasi, yaitu pengembangan berulang, prototyping sistem, dan prototyping sekali pakai. Melalui pengembangan berulang, seluruh proyek dipecah menjadi beberapa seri / versi yang akan dikembangkan secara berurutan. Hal terpenting dalam pendekatan ini adalah mengembangkan versi pertama sistem. Versi ini dikembangkan dengan cepat menggunakan metode mini waterfall. Setelah diimplementasikan, pengguna dapat memberikan umpan balik untuk pengembangan sistem pada versi berikutnya. dalam teknik ini, diperlukan pemahaman yang baik tentang ruang lingkup proyek, maka dari itu tim pengembang dapat membangun sistem dengan kemampuan fungsional yang komprehensif hanya dalam waktu singkat, misalnya 60 hingga 90 hari [9].

Beberapa penelitian telah dilakukan untuk pengembangan sistem informasi penggajian. Penelitian yang dilakukan Shukla mengembangkan sistem payroll dengan sistem pemantauan kehadiran melalui RFID dan Biometrik [10]. Penelitian yang dilakukan oleh Soegoto merancang sistem payroll menggunakan pendekatan prototyping dengan pemodelan Unified Modelling Language untuk CV. Bandung ID Card [11]. Penelitian yang lain membahas mengenai pengembangan sistem informasi penggajian untuk PT. Sinar Metrindo Perkasa, dimana model pengembangan perangkat lunak menggunakan metode waterfall [12]. PT. Sinar Metrindo Perkasa (SIMETRI) adalah perusahaan yang bergerak dibidang produksi panel listrik. Beberapa penelitian lain juga mengangkat pengembangan sistem informasi penggajian karyawan menggunakan metode waterfall [13], analisis terstruktur [14] dan HIPO [15].

STMIK STIKOM Indonesia merupakan sebuah Perguruan Tinggi dengan 127 karyawan yang terdiri dari dosen dan staf. Sebagai alat bantu dalam proses penggajian, manajemen masih menggunakan aplikasi Microsoft Excel. Sistem ini memiliki kelemahan berupa rumitnya proses update data dan belum tersedianya slip gaji otomatis untuk tiap karyawan. Penggunaan sistem informasi diharapkan dapat mempercepat proses penyusunan daftar gaji tiap bulannya dengan mengakomodir setiap perubahan data yang ada. Sistem Informasi juga diharapkan mampu mengirimkan email slip gaji pada setiap karyawan dengan cepat. Sistem Informasi yang akan dikembangkan diharapkan mampu mengelola potongan-potongan terhadap gaji, misalkan BPJS, potongan koperasi dan iuran Suka Duka.

Penelitian ini bertujuan untuk mendapatkan rancangan sistem informasi penggajian dan mengembangkan sistem informasi penggajian berbasis web yang mampu memenuhi kebutuhan fungsional dari proses penggajian di STMIK STIKOM Indonesia dengan metode pengembangan perangkat lunak $R A D$. Pada penelitian terdahulu metode pengembangan perangkat lunak didominasi oleh metode waterfall. Sangat sedikit penelitian yang menggunakan metode $R A D$ untuk mengembangkan sistem informasi penggajian. Sehingga pada penelitian ini metode pengembangan perangkat lunak yang digunakan adalah metode $R A D$

$R A D$ juga dipilih karena metode ini cocok dengan target waktu pengembangan aplikasi yang berkisar 3 bulan dan alasan karakteristik RAD dimana pengguna aplikasi dilibatkan dengan porsi besar dalam proses pengembangan aplikasi. Karakteristik metode RAD juga menyebutkan bahwa metode ini cocok untuk pengembangan aplikasi dalam skala tidak terlalu besar dan didukung oleh tim yang kecil [16][17]. Sehingga dalam penelitian ini ingin pula diketahui apakah metode RAD cocok untuk dijadikan acuan metode pengembangan perangkat lunak dalam pengembangan aplikasi penggajian STMIK STIKOM Indonesia. 
Pada penelitian ini sistem informasi penggajian dikembangkan untuk perguruan tinggi yang tergolong sebagai industri jasa. Pada perguruan tinggi STMIK STIKOM Indonesia tidak memperhitungkan unsur gaji yang didapatkan dari penghitungan absensi, sangat berbeda dengan perusahaan yang bergerak di bidang manufaktur maupun dagang.

Sistem Informasi berbasis website menjadi pilihan dikarenakan fleksibilitas dalam pengaksesan. Sistem berbasis website memberikan keleluasaan bagi manajemen terkait ruang dan waktu dalam penyusunan gaji. Penggunaan basis data juga memberikan kemudahan dalam berbagi akses data (sharability), sehingga dalam waktu yang bersamaan beberapa pengguna dapat mengakses data dengan berbagai jenis tindakan sesuai hak aksesnya.

\section{METODE PENELITIAN}

\subsection{Alur Penelitian}

Pengembangan Sistem informasi penggajian ini dilaksanakan dengan mengikuti metode pengembangan perangkat lunak dengan metode rapid application development. Metode $R A D$ ini menitikberatkan kepada pengembangan aplikasi secara cepat dengan tetap mematuhi tahapan yang terdiri dari analisis kebutuhan, perancangan cepat, coding, pengujian dan implementasi. Metode ini mensyaratkan perangkat lunak telah berhasil dikembangkan dalam waktu kurang lebih dua atau tiga bulan. Adapun tahapan penelitian dapat ditunjukkan oleh gambar 1 .

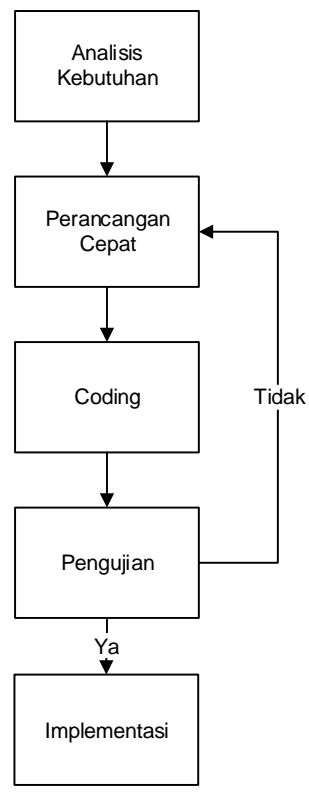

Gambar 1. Tahapan penelitian

Pada tahapan analisis kebutuhan dilakukan penggalian informasi berupa kebutuhan sistem baik yang terdiri dari data yang akan diolah, output yang akan dihasilkan, proses yang terjadi di dalamnya, user yang terlibat, dan fungsionalitas sistem lainnya. Penggalian informasi ini dilakukan dengan cara wawancara dan observasi.

Wawancara dilakukan terhadap pihak yang menggunakan sistem. Adapun beberapa poin dari wawancara adalah sebagai berikut:

1. Dalam menyusun total gaji karyawan komponen gaji apa saja yang digunakan untuk melaksanakan perhitungan.

2. Bagaimana cara untuk mendapatkan nilai tiap komponen gaji tersebut.

3. Adakah aturan khusus yang diterapkan dalam penghitungan total gaji.

4. Siapa saja yang akan menggunakan sistem dan fungsi apa saja yang dilakukan oleh masing - masing user tersebut.

Penggalian informasi dengan metode observasi dilakukan dengan mengamati proses penghitungan gaji yang terjadi. Dalam observasi ini pula dikumpulkan beberapa data seperti data pokok karyawan, data gaji pokok dan lain sebagainya.

Indikator keberhasilan dalam tahapan analisis kebutuhan fungsional adalah didapatkannya gambaran menyeluruh tentang fungsionalitas sistem, ruang lingkup sistem, dan informasi lainnya sehingga memudahkan untuk melaksanakan tahapan berikutnya yaitu perancangan.

Pada tahap perancangan dilakukan perancangan fungsionalitas sistem berupa prosedur dan fungsi, perancangan basis data, perancangan antarmuka. Alat bantu yang digunakan dalam tahap perancangan adalah berupa data flow diagram, entity relationship diagram, dan diagram relasional. Indikator keberhasilan pada tahapan ini adalah didapatkannya gambaran menyeluruh mengenai prosedur dan fungsi yang dapat diimplementasikan dalam bahasa pemrograman. Dalam tahapan ini dilakukan perancangan sesuai dengan analisis kebutuhan sistem yang mengedepankan teori-teori dalam pengembangan perangkat lunak. 
Pada tahap coding atau pengembangan dilaksanakan penyusunan syntax pemrograman dalam bahasa PHP sesuai dengan rancangan yang dihasilkan pada tahap perancangan. Untuk mempercepat proses pengembangan maka digunakan framework untuk membangun aplikasi. Indikator keberhasilan dari tahapan ini adalah dihasilkannya aplikasi yang mampu melaksanakan instruksi dan menghasilkan luaran sesuai dengan kebutuhan pengguna.

Pada tahap pengujian dilakukan uji coba dengan data bulan sebelumnya sehingga mendapatkan fungsionalitas sistem yang tepat. Pengujian melibatkan user sistem secara langsung, untuk kemudian mendapatkan masukan terhadap perbaikan sistem. Kegagalan sebagian sistem dalam tahapan ini akan menyebabkan proses kembali ke dalam tahap perancangan dan dilanjutkan ke tahap coding. Agar tidak ada yang terlewat dalam pengujian maka dibuatkan list fungsionalitas sistem yang akan diuji dalam tabel pengujian black box. Indikator keberhasilan dari tahapan ini adalah didapatkannya aplikasi yang telah bebas dari kesalahan fungsionalitas sistem sewaktu diimplementasikan.

Pada tahap implementasi dilakukan pengimplementasian sistem ke dalam penyusunan gaji yang dipantau dalam satu bulan berjalan. Pada tahap implementasi ini juga akan dilakukan pengukuran tingkat kepuasan user dalam menggunakan aplikasi. Indikator dari keberhasilan tahapan ini adalah sistem telah mampu menyelesaikan permasalahan penyusunan gaji tiap bulannya.

\subsection{Teknik Pengumpulan Data}

Pengumpulan data dilakukan dengan metode pengumpulan data primer dan metode pengumpulan sekunder. Metode pengumpulan data primer berupa wawancara dan observasi dilakukan untuk sistem penggajian karyawan STMIK STIKOM Indonesia pada bidang Lembaga Pengembangan Tenaga Pendidik dan Kependidikan (LPTPK) dan Ketua STMIK STIKOM Indonesia. Wawancara dan observasi terutama dilakukan untuk mengetahui secara pasti kebutuhan LPTPK dan Ketua STMIK STIKOM Indonesia terhadap sistem penggajian yang akan dikembangkan dan untuk membatasi ruang lingkup sistem. Metode pengumpulan data sekunder dilakukan dengan cara kajian pustaka untuk memahami teknik pengembangan perangkat lunak dengan metode $R A D$.

\subsection{Analisa Kebutuhan Sistem}

Berdasarkan pengamatan yang dilakukan terhadap manajemen dalam hal penyusunan gaji karyawan STMIK STIKOM Indonesia maka kebutuhan fungsional sistem informasi dalam penelitian ini dapat didefinisikan sebagai berikut:

1. Data karyawan STMIK STIKOM Indonesia dibedakan sebagai data dosen dan data staff.

2. Penentuan gaji pokok mengikuti pola penentuan gaji pokok pada Aparatur Sipil Negara.

3. Staf LPTPK membutuhkan fasilitas untuk mengupdate data dosen dan data staf yang terkait dengan penggajian. Beberapa data tersebut antara lain, penambahan dan pemberhentian dosen dan staf, perubahan golongan, perubahan jabatan fungsional, perubahan jabatan struktural, perubahan jumlah anak, perubahan tunjangan BPJS dan update data master gaji pokok berdasarkan golongan.

4. Petugas koperasi membutuhkan fasilitas untuk menambah dan merubah data potongan koperasi dan iuran suka duka tiap bulannya.

5. Pengguna Ketua STMIK STIKOM Indonesia membutuhkan fasilitas untuk merubah data master tunjangan fungsional, data master tunjangan struktural, data master tunjangan kinerja, generate gaji tiap bulannya, evaluasi rekapitulasi gaji tiap bulannya, mengirimkan slip gaji secara batch.

Berdasarkan analisis kebutuhan fungsional yang telah didefinisikan maka rancangan sistem dibentuk menggunakan rancangan data flow diagram dan rancangan basis data.

\subsection{Data Flow Diagram}

Data flow diagram dalam perancangan sistem informasi ini berguna untuk menggambarkan prosedur yang harus dikembangkan dalam bahasa pemrograman beserta aliran data yang mengalir antar proses tersebut. Data flow diagram juga memberikan gambaran menyeluruh mengenai ruang lingkup sistem. Perancangan data flow diagram dalam penelitian ini dibatasi pada diagram konteks seperti ditunjukkan oleh gambar 2 dan data flow diagram level 1 seperti ditunjukkan oleh gambar 3.

Gambar 2 menunjukkan bahwa ada 4 eksternal entity yang terlibat ke dalam sistem yaitu Staff LPTPK, Ketua, Karyawan, dan Staff Koperasi. Staff LPTPK bertanggungjawab atas manajemen data tunjangan BPJS dan master gaji pokok karyawan. Staff Koperasi memberikan data potongan koperasi dan suka duka tiap bulannya ke dalam sistem. Entitas karyawan memberikan data pokok karyawan dan menerima slip gaji dari sistem. Sedangkan entitas Ketua memberikan data tunjangan ke dalam sistem dan menerima data rekapitulasi gaji dari sistem sebagai bahan melaksanakan kegiatan penggajian tiap bulannya. 


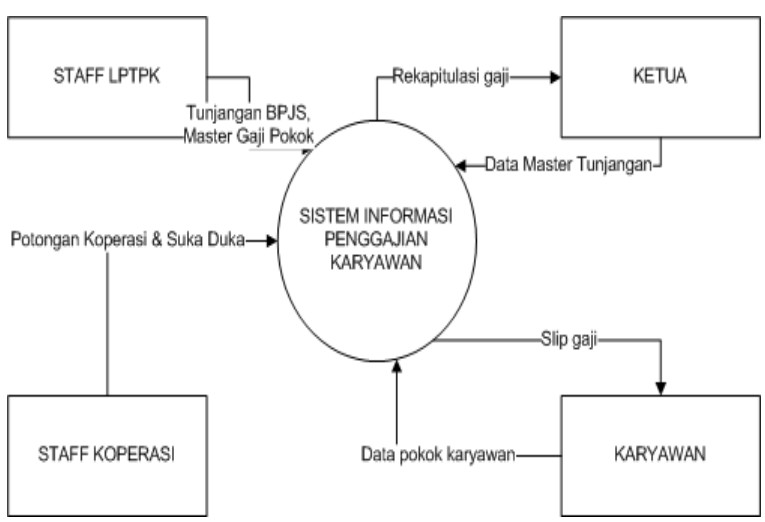

Gambar 2. Konteks Diagram

Gambar 3 memberikan informasi bahwa sistem dikembangkan berdasarkan 6 bagian besar yaitu manipulasi data pokok karyawan, manipulasi data master tunjangan, manipulasi data master gaji pokok, generate gaji, input potongan koperasi dan suka duka, serta pembuatan rekap gaji dan slip gaji. Tiga proses manipulasi di awal menjadi tahapan awal dimana harus dilakukan terlebih dahulu sebelum proses generate gaji bulanan dilakukan. Setelah gaji bulanan berhasil degenerate untuk semua karyawan maka tahapan input potongan koperasi dan suka duka dilaksanakan sehingga rekapitulasi gaji akhir dan slip gaji didapatkan.

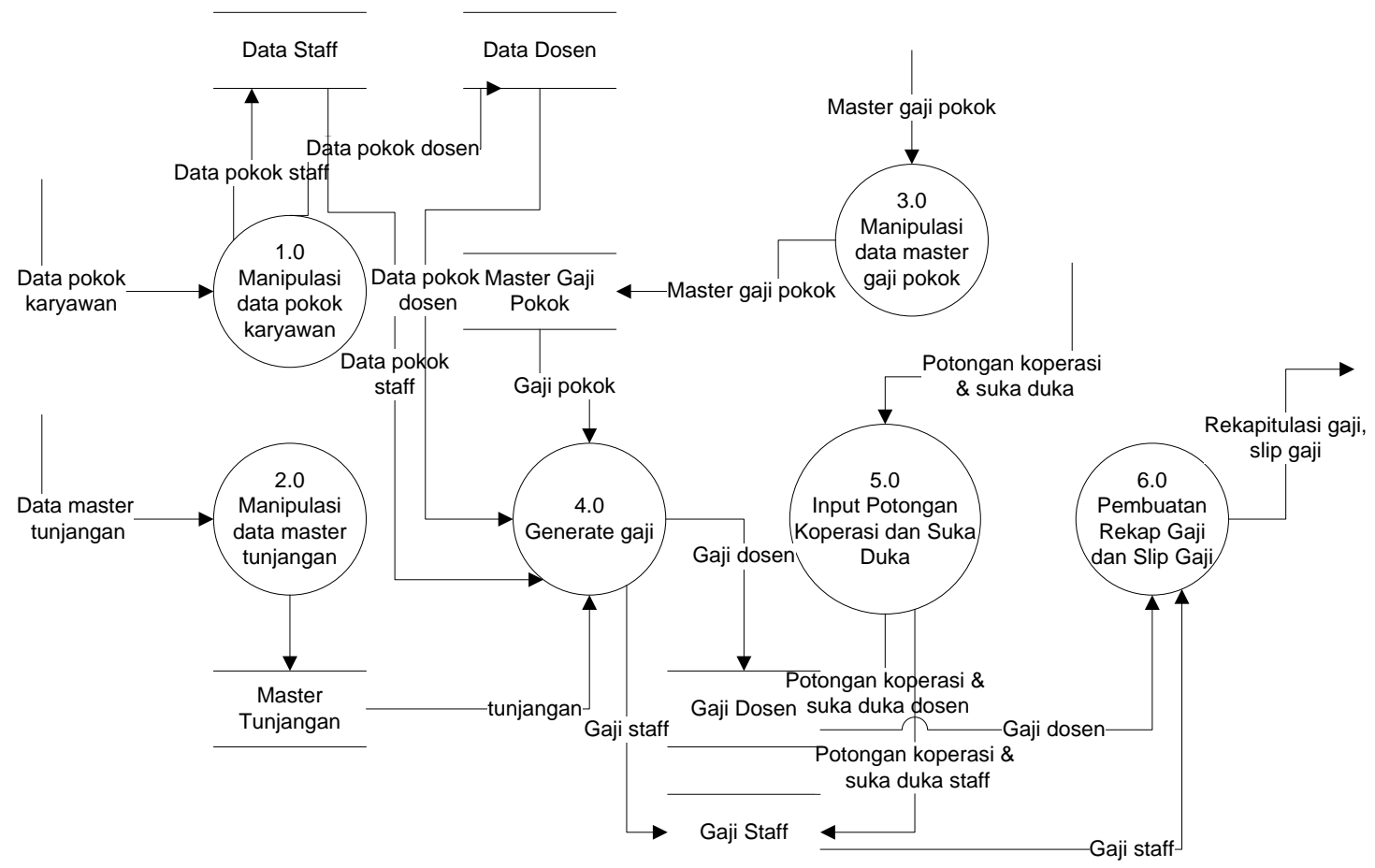

Gambar 3. DFD Level 1

\subsection{Perancangan Basis Data}

Rancangan basis data dibuat langsung dalam MySQL dengan menggunakan editor SQLYog. Gambar 4 menunjukkan bahwa terbentuk 10 tabel untuk mengembangkan sistem informasi penggajian karyawan STMIK STIKOM Indonesia. Tabel tersebut antara lain tabel dosen, staff, gaji_dosen, gaji_staff, tunjangan_struktural, tunjangan_jabatan, golongan, gaji_pokok_dosen, gaji_pokok_staff dan users. 


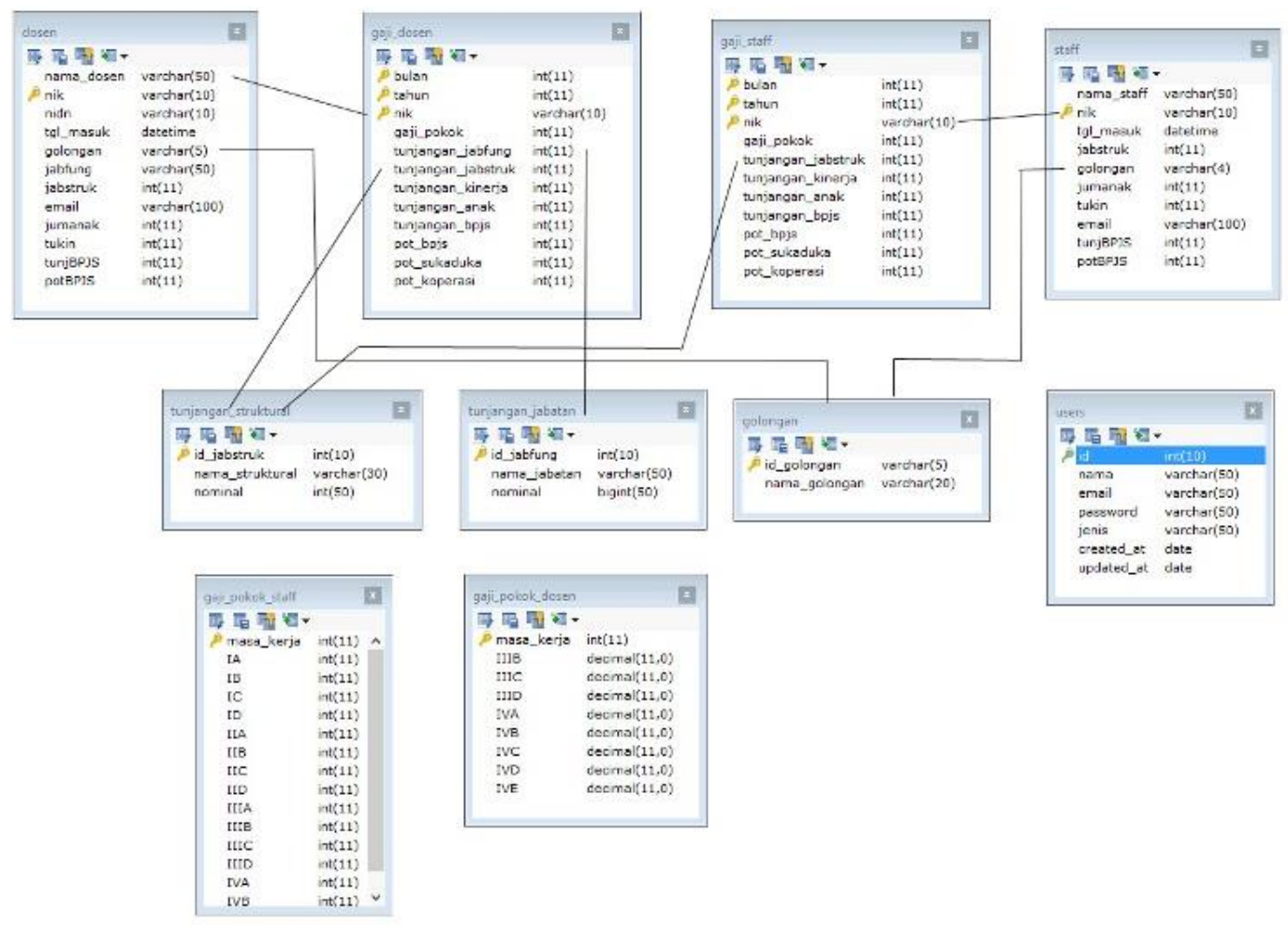

Gambar 4. Rancangan Basis Data

\section{HASIL DAN ANALISIS}

Berdasarkan analisis dan perancangan yang dilakukan sebelumnya diperoleh beberapa informasi yaitu dari sifat data yang tergambar dalam rancangan basis data seperti ditunjukkan oleh gambar 4, maka data dapat dibedakan berdasarkan sifat transaksionalnya. Tabel dosen, staff, tunjangan_struktural, tunjangan_jabatan, golongan, gaji_pokok_staff dan gaji_pokok_dosen termasuk ke dalam tabel data master dimana data merupakan data acuan (rujukan) untuk proses transaksional dalam hal ini adalah pembentukan gaji tiap bulannya. Sedangkan tabel gaji_dosen dan gaji_staff merupakan tabel data transaksional dimana karakteristiknya menyimpan hasil transaksi yang terjadi dalam aplikasi yaitu gaji tiap bulannya. Berdasarkan pola seperti ini maka menu dalam aplikasi dipisahkan ke dalam menu untuk manipulasi data master dan manipulasi data transaksional (payroll). Sehingga aplikasi sistem payroll untuk STMIK STIKOM Indonesia dibagi menjadi tiga menu pokok yaitu menu data master, menu payroll, dan menu laporan.

\subsection{Implementasi Menu Data Master}

Menu data master mencakup beberapa submenu diantara lain adalah: submenu dosen, submenu staff, submenu tunjangan jabatan, submenu tunjangan struktural, submenu gaji pokok dosen, submenu gaji pokok staf, submenu tunjangan kinerja dosen dan submenu tunjangan kinerja staff.

Dalam submenu dosen disediakan fasilitas untuk memanipulasi data dosen, diantaranya ada fasilitas untuk menambahkan dosen, mengubah data pokok dosen dan menghapus data dosen. Dalam submenu ini pula dapat dilakukan pencarian terhadap data dosen.

Dalam submenu staff seperti halnya submenu dosen, disediakan fasilitas untuk memanipulasi data staff, diantaranya ada fasilitas untuk menambahkan staff, mengubah data pokok staff dan menghapus data staff. Dalam submenu ini pula dapat dilakukan pencarian terhadap data staff.

Submenu Gaji Pokok Dosen menyediakan fasilitas untuk mengubah besaran gaji pokok dosen sesuai masa kerja dan golongan berdasarkan ketetapan pemerintah atas besaran gaji pokok aparatur sipil negara. Submenu ini ditunjukkan oleh gambar 5 . 


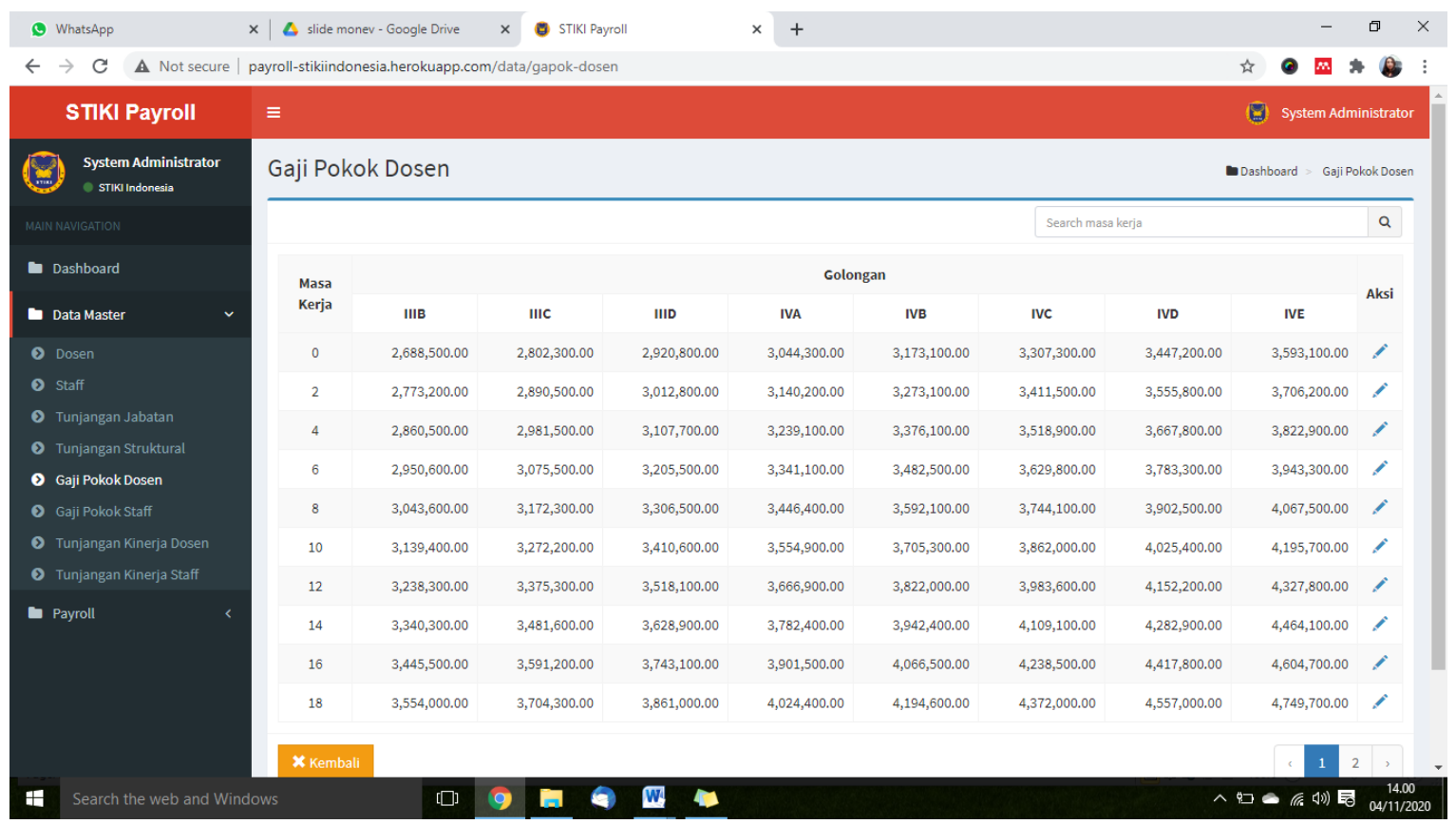

Gambar 5. Submenu Gaji Pokok Dosen

Submenu Gaji Pokok Staff menyediakan fasilitas untuk mengubah besaran gaji pokok staff sesuai masa kerja dan golongan berdasarkan ketetapan pemerintah atas besaran gaji pokok aparatur sipil negara. Dalam submenu tunjangan kinerja dosen dan staff diberikan fasilitas untuk mengubah tunjangan kinerja berdasarkan prestasi kerja yang dicapai. Fasilitas ini digunakan oleh Ketua STMIK STIKOM Indonesia untuk mengubah tunjangan kinerja berdasarkan prestasi dan kinerja yang diperoleh karyawan. Submenu ini seperti ditunjukkan oleh gambar 6.

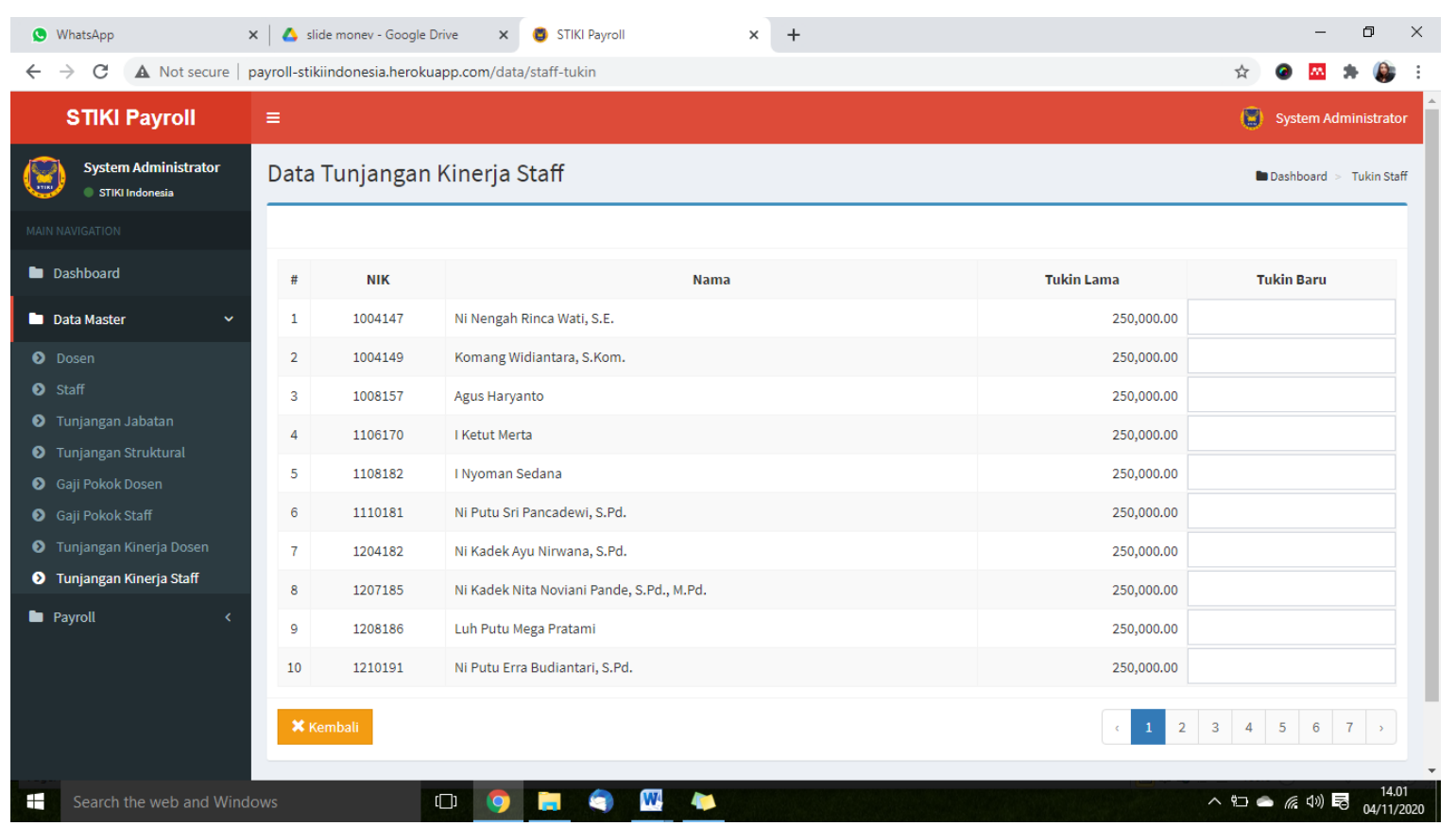

Gambar 6. Submenu Tunjangan Kinerja Staff

\subsection{Implementasi Menu Payroll}

Menu payroll merupakan inti dari pemrosesan dalam sistem informasi ini. Dalam menu ini terdapat submenu proses generate gaji, submenu arsip gaji, dan submenu potongan koperasi dan suka duka. Dalam submenu generate gaji diberikan fasilitas untuk membentuk gaji secara otomatis tiap bulannya. Setelah digenerate gaji dosen dan staff akan terbentuk untuk semua instrumennya kecuali potongan suka duka dan koperasi. Gambaran mengenai submenu ini seperti ditunjukkan oleh gambar 7. 


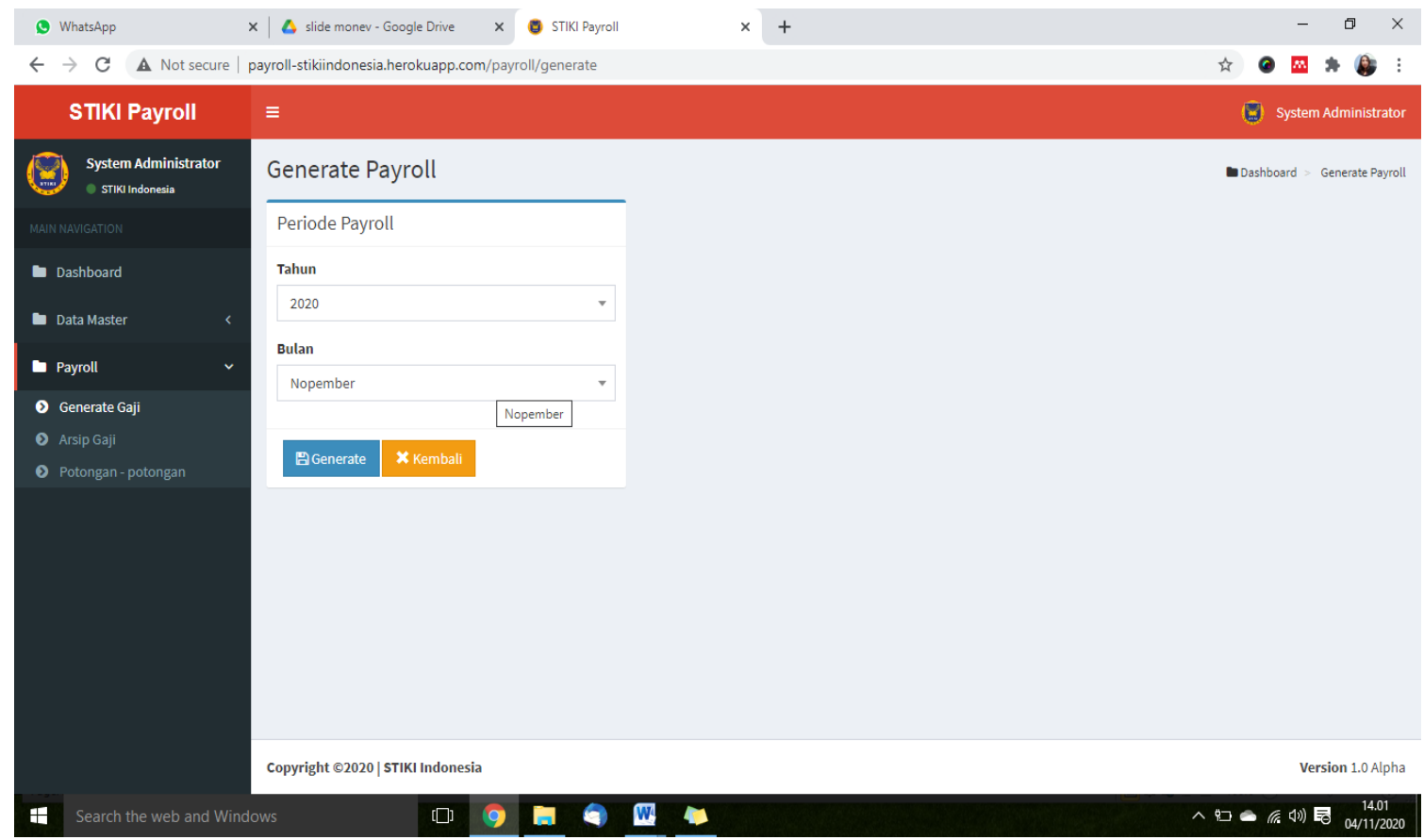

Gambar 7. Submenu Generate Gaji

Dalam submenu arsip payroll diberikan fasilitas untuk memantau gaji yang telah terbentuk melalui proses generate gaji. Jika dirasakan ada kesalahan maka proses generate dapat dilakukan ulang untuk bulan berjalan. Submenu ini seperti ditunjukkan oleh gambar 8 .

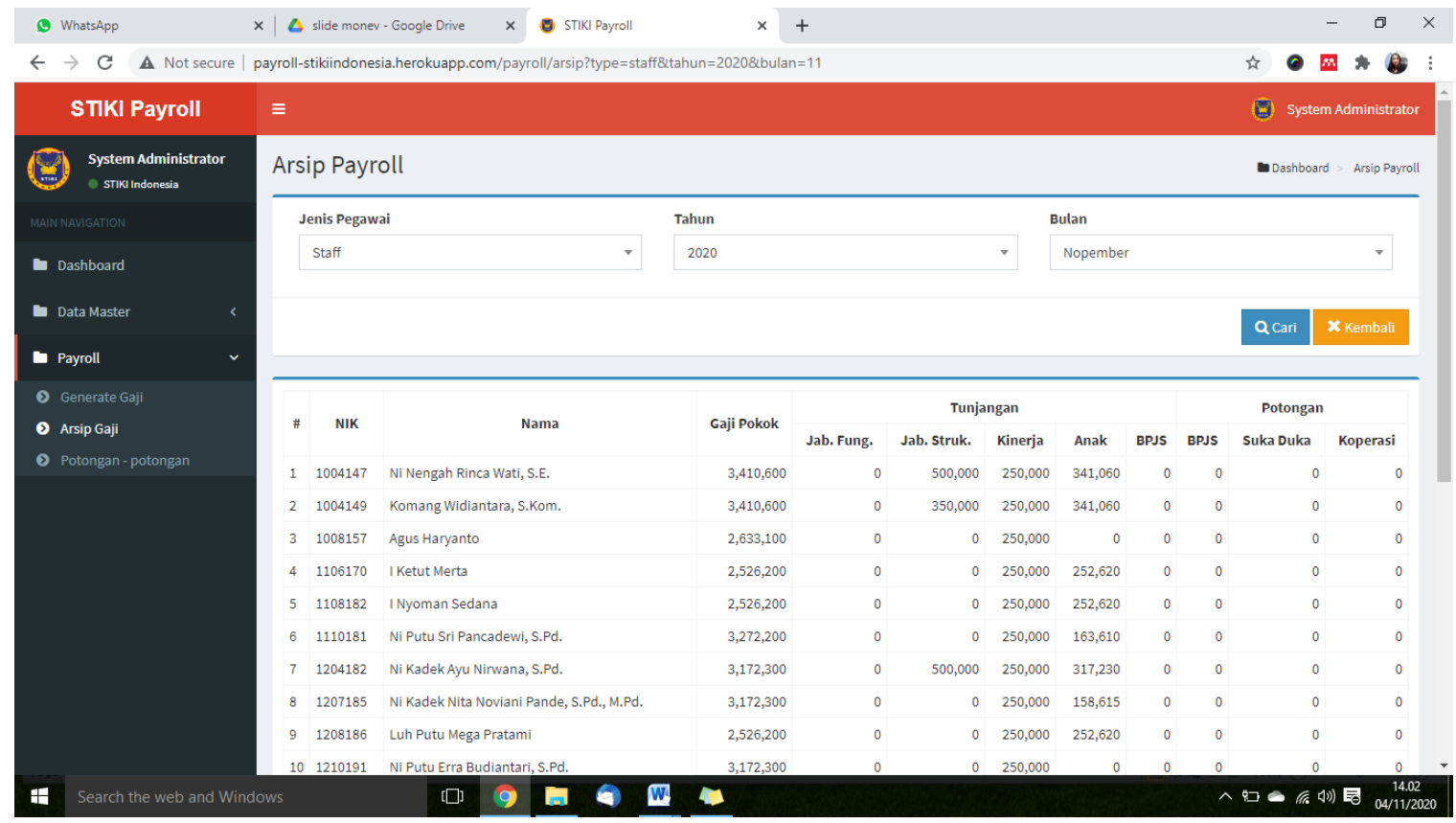

Gambar 8. Submenu Arsip Payroll

Submenu terakhir dari menu payroll adalah submenu potongan koperasi dan suka duka. Pada submenu ini diberikan fasilitas untuk menginpur potongan koperasi dan suka duka di bulan berjalan. Pengisian potongan hanya bisa dilakukan setelah dilakukan generate gaji. Selain menginput langsung ke dalam form seperti ditunjukkan oleh gambar 9, proses input bisa juga dilakukan melalui menu import dari file excel dengan terlebih dahulu mengunduh file template dengan menu export. 


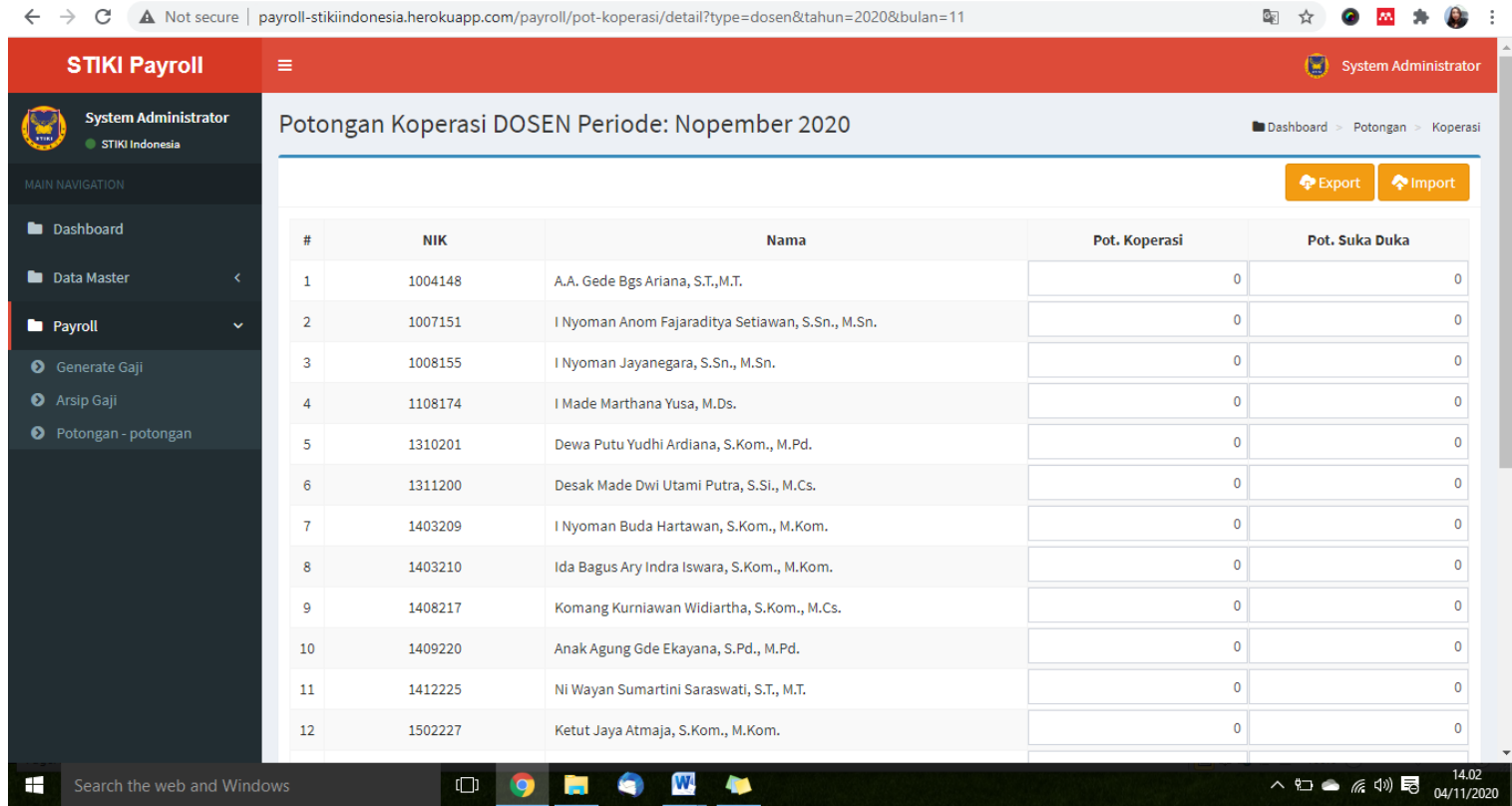

Gambar 9. Submenu Potongan Koperasi dan Suka Duka

\subsection{Implementasi Menu Laporan}

Menu laporan untuk sistem ini terdiri dari submenu laporan gaji, submenu laporan perbandingan gaji, cetak slip gaji dan kirim slip gaji. Submenu laporan gaji memberikan fasilitas untuk mencetak rekapitulasi gaji perbulannya untuk dosen dan karyawan. Berikut fungsi ini seperti ditunjukkan oleh gambar 10. Submenu laporan perbandingan gaji memberikan fasilitas pada ketua STMIK STIKOM Indonesia untuk memonitoring dan mengevaluasi perubahan gaji berjalan dibandingkan gaji bulan sebelumnya. Proses ini memastikan bahwa tidak ada kesalahan nominal pemberian gaji. Submenu cetak slip gaji berfungsi untuk mencetak slip gaji dosen dan staff sesuai periode gaji yang dipilih. Submenu kirim slip gaji berfungsi untuk mengirimkan email ke masing - masing karyawan slip gaji periode tertentu.

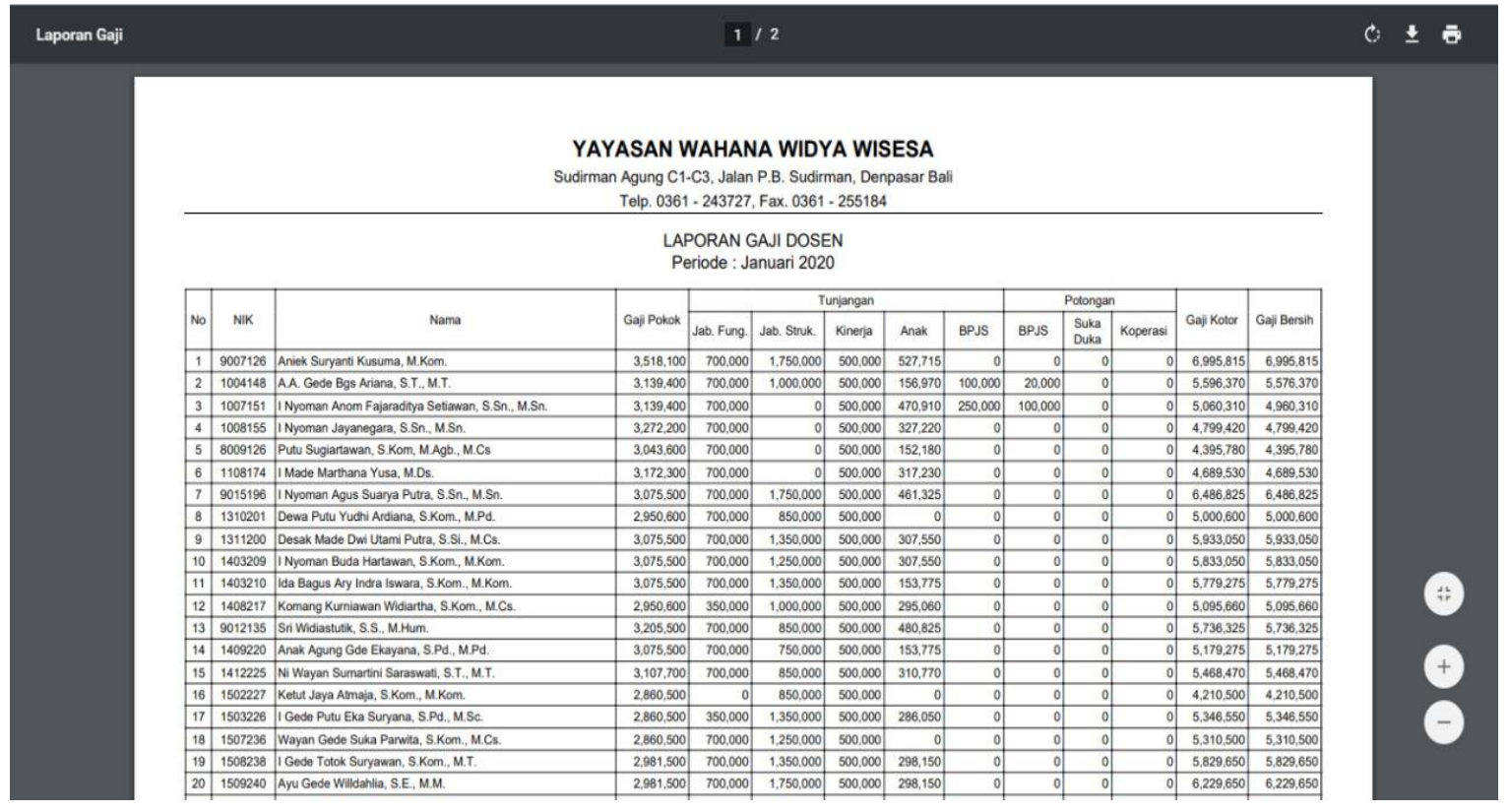

Gambar 10. Submenu Laporan Rekapitulasi Gaji 


\subsection{Pengujian Sistem}

Pengujian sistem dilakukan terhadap fungsionalitas sistem untuk mengetahui apakah sistem telah memenuhi kebutuhan fungsionalitas sistem dan bebas dari kesalahan dengan metode blackbox testing. Berikut hasil pengujian sistem seperti ditunjukkan oleh tabel 1.

\begin{tabular}{|c|c|c|}
\hline No & SubMenu & Hasil Pengujian \\
\hline 1. & Dosen & $\begin{array}{l}\text { Sistem telah mampu menambahkan, mengupdate dan menghapus data dosen } \\
\text { dengan tepat dan valid }\end{array}$ \\
\hline 2. & Staff & $\begin{array}{l}\text { Sistem telah mampu menambahkan, mengupdate dan menghapus data staff } \\
\text { dengan tepat dan valid }\end{array}$ \\
\hline 3. & Gaji Pokok Dosen & $\begin{array}{l}\text { Sistem telah mampu mengupdate data master gaji pokok dosen dengan tepat dan } \\
\text { valid }\end{array}$ \\
\hline 4. & Gaji Pokok Staff & $\begin{array}{l}\text { Sistem telah mampu mengupdate data master gaji pokok staff dengan tepat dan } \\
\text { valid }\end{array}$ \\
\hline 5. & Tunjangan Jabatan & $\begin{array}{l}\text { Sistem telah mampu menambahkan, mengupdate dan data master tunjangan } \\
\text { jabatan dosen dengan tepat dan valid }\end{array}$ \\
\hline 6. & Tunjangan Struktural & $\begin{array}{l}\text { Sistem telah mampu menambahkan, mengupdate dan data master tunjangan } \\
\text { struktural dosen dan staff dengan tepat dan valid }\end{array}$ \\
\hline 7. & Tunjangan Kinerja Dosen & Sistem telah mampu mengupdate tunjangan kinerja dosen dengan tepat dan valid \\
\hline 8. & Tunjangan Kinerja Staff & Sistem telah mampu mengupdate tunjangan kinerja staff dengan tepat dan valid \\
\hline 9. & Generate Gaji & $\begin{array}{l}\text { Sistem telah mampu membentuk data gaji dosen dan staff untuk bulan berjalan } \\
\text { dengan tepat dan valid }\end{array}$ \\
\hline 10 . & Arsip Gaji & Sistem mampu menyajikan data gaji dosen dan staff dengan tepat dan valid \\
\hline 11. & Potongan Koperasi dan Suka Duka & $\begin{array}{l}\text { Sistem mampu menambahkan potongan koperasi dan suka duka secara tepat dan } \\
\text { valid. }\end{array}$ \\
\hline 12. & Laporan Gaji & $\begin{array}{l}\text { Sistem mampu memberikan laporan rekapitulasi gaji perbulan secara tepat dan } \\
\text { valid }\end{array}$ \\
\hline 13. & Laporan Perbandingan Gaji & $\begin{array}{l}\text { Sistem mampu memberikan laporan perbandingan total gaji bulan berjalan dan } \\
\text { bulan sebelumnya secara tepat dan valid }\end{array}$ \\
\hline 14. & Cetak Slip Gaji & Sistem mampu menghasilkan slip gaji karyawan dengan tepat dan valid \\
\hline 15. & Kirim Slip Gaji & $\begin{array}{l}\text { Sistem mampu mengirimkan email slip gaji kepada karyawan dengan tepat dan } \\
\text { valid. }\end{array}$ \\
\hline
\end{tabular}

\section{KESIMPULAN}

Berikut kesimpulan yang bisa didapat dari penelitian untuk mengembangkan sistem penggajian karyawan STMIK STIKOM Indonesia berbasis website dengan metode RAD :

1. Untuk menjawab tujuan penelitian dalam hal mendapatkan rancangan sistem informasi penggajian dan mengembangkan sistem informasi penggajian berbasis web yang mampu memenuhi kebutuhan fungsional dari proses penggajian di STMIK STIKOM Indonesia maka diperoleh kesimpulan sebagai berikut. Berdasarkan rancangan sistem yang tertuang dalam diagram konteks dan data flow diagram maka dapat disimpulkan kebutuhan fungsional sistem untuk sistem penggajian ini secara garis besar dapat dilihat dari sudut pandang Ketua STMIK STIKOM Indonesia, staff LPTPK, dan staff Koperasi. Kebutuhan dari sisi Ketua adalah bagaimana sistem dapat memberikan laporan rekapitulasi dan slip gaji secara cepat dan tepat dalam hal ini adalah bagian transaksional sistem. Kebutuhan dari sisi staff LPTPK bagaimana sistem memberikan fasilitas manipulasi data master yang berkaitan dengan pembentukan instrumen gaji. Kebutuhan dari sisi staff koperasi adalah bagaimana sistem memberikan fasilitas untuk menginput potongan koperasi dan suka duka. Berdasarkan pengujian fungsionalitas sistem menggunakan metode blackbox testing yang menunjukkan valid untuk semua kebutuhan fungsionalitas yang dituangkan dalam menu aplikasi pada tabel 1, diperoleh kesimpulan bahwa sistem yang dikembangkan telah mampu memenuhi kebutuhan fungsional sistem dengan baik dan valid.

2. Untuk menjawab tujuan penelitian apakah metode pengembangan perangkat lunak RAD cocok digunakan dalam pengembangan aplikasi ini maka dapat disimpulkan bahwa metode RAD cocok digunakan dalam pengembangan aplikasi payroll STMIK STIKOM Indonesia dengan dasar analisis bahwa pengembangan aplikasi selesai dalam waktu 3 bulan dan melibatkan pengguna aplikasi secara intensif yang dibuktikan dengan tahapan wawancara dan observasi mendetail, serta alasan lain bahwa aplikasi termasuk dalam skala aplikasi yang tidak terlalu besar yang cocok dengan karakteristik alasan penggunaan metode RAD.

Untuk pengembangan penelitian berikutnya disarankan untuk meneliti rancangan sistem penggajian yang mengintegrasikan dengan tingkat kehadiran karyawan, yang didapatkan secara otomatis dari mesin fingerprint. Penelitian berikutnya juga bisa menyertakan sistem penilaian kinerja karyawan secara otomatis mempengaruhi tunjangan kinerja dalam sistem payroll. 


\section{UCAPAN TERIMA KASIH}

Terima kasih kami ucapkan kepada STMIK STIKOM Indonesia atas pendanaan penelitian ini serta kesediaannya dalam menyediakan data penelitian.

\section{REFERENSI}

[1] M. S. Jibrin, S. B. Ejura, and N. I. Augustine, "System of Payroll in the Public Sector Administration," Asian Development Policy Review, vol. 3, no. 1, pp. 9-19, 2015.

[2] K. Mahajan, S. Shukla, and N. Soni, “A Review of Computerized Payroll System,” IJARCCE, vol. 4, no. 1, pp. 67-70, Jan. 2015.

[3] A. V. Singh, S. V. Chaphekar, and Y. S. Sawant, “Automated Payroll System (A-PAY)," International Journal of Modern Trends in Engineering and Research, vol. 3, no. 2, pp. 548-553, 2016.

[4] F. H. Rusly, A. Ahmi, Y. Y. A. Talib, and K. Rosli, "Payroll system: A bibliometric analysis of the literature," in AIP :American Istitute of Physics Conference Proceedings, 2018, pp. 020-124.

[5] F. H. Rusly, A. Ahmi, Y. Y. A. Talib, and K. Rosli, "Global perspective on payroll system patent and research: A bibliometric performance," International Journal of Recent Technology and Engineering, vol. 8, no. 2, pp. 148-157, 2019.

[6] M. P. Putri and H. Effendi, "Implementasi Metode Rapid Application Development Pada Website Service Guide 'Waterfall Tour South Sumatera," SISFOKOM : Jurnal Sistem Informasi dan Komputer, vol. 07, no. 2, pp. 130-136, 2018.

[7] S. Aswati and Y. Siagian, "Model Rapid Application Development Dalam Rancang Bangun Sistem Informasi Pemasaran Rumah (Studi Kasus : Perum Perumnas Cabang Medan,” in SESINDO : Seminar Nasional Sistem Informasi Indonesia, 2016, pp. $317-324$.

[8] S. Kosasi, "Penerapan Rapid Application Development Dalam Sistem Perniagaan Elektronik Furniture," Creative Information Technology Journal, vol. 2, no. 4, pp. 265-276, 2015.

[9] R. Delima, H. B. Santosa, and J. Purwadi, "Development of Dutatani Website Using Rapid Application Development," IJITEE :International Journal of Information Technology and Electrical Engineering, vol. 1, no. 2, pp. 36-44, 2017.

[10] V. K. Shukla and N. Bhandari, "Conceptual Framework for Enhancing Payroll Management and Attendance Monitoring System through RFID and Biometric," in AICIA:Amity International Conference on Artificial Intelligence, 2019, no. February, pp. $188-192$.

[11] Y. Soegoto, "Designing Payroll Information System: Case Study on CV. Bandung ID card," in IOP Conference Series: Materials Science and Engineering, Nov. 2019, pp. 01-09.

[12] A. Moenir and F. Yuliyanto, "Perancangan Sistem Informasi Penggajian Berbasis Web dengan Metode Waterfall pada PT. Sinar Metrindo Perkasa (Simetri),” Jurnal Informatika Universitas Pamulang, vol. 2, no. 3, p. 127, 2017.

[13] M. Bagir and J. Rahmadian, "Rancang Bangun Sistem Informasi Penggajian E- Payroll Studi Kasus : STTI NIIT I-TECH,” in SESINDO: Seminar Nasional Sistem Informasi Indonesia, 2016, pp. 389-396.

[14] M. Firman, D. Pramurza, S. Sakti, and A. Kerinci, "Payroll Accounting Information System at PT . Telekomunikasi Indonesia Tbk," Journal of Applied Accounting and Business, vol. 1, no. 1, pp. 44-52, 2019.

[15] C. Haryadi and R. W. Arifin, "Sistem Informasi Penggajian Karyawan pada PT. White Horse Ceramic Indonesia," Bina Insani ICT Journal, vol. 3, no. 2, pp. 370-383, 2016.

[16] R. W. W. Fadhil Muhammad, Soni Fajar Surya Gumilang, "Penerapan Sistem Payroll berbasis OpenERP Pada CV. Huda Jaya dengan Metode Rapid Application Development," in e-Proceeding of Engineering Telkom University, 2015, pp. 5615-5621.

[17] N. K. Utomo, “Rancang Bangun Sistem Informasi Penggajian di Kampoeng Koding,” Universitas Muhammadiyah Surakarta, 2018. 
Matrik : Jurnal Manajemen, Teknik Informatika, dan Rekayasa Komputer, Vol. 20, No. 2, Mei 2021: 213 224 